\title{
O USO DO STOP-MOTION COMO PRÁTICA PEDAGÓGICA NO ENSINO DE GEOGRAFIA NO CONTEXTO DO EMI
}

\author{
J. L. PAULA*, J. L. PAULA e A. L. S. HENRIQUE \\ Rede Municipal de Educação de Natal/RN e de Parnamirim/RN \\ jolipa7@hotmail.com*
}

Submetido 10/03/2017 - Aceito 27/08/2017

DOI: $10.15628 /$ holos.2017.5774

\section{RESUMO}

O presente trabalho se configura como um relato de experiência de um projeto de ensino desenvolvido na disciplina de Geografia, no Instituto Federal de Educação, Ciência e Tecnologia do Rio Grande do Norte (IFRN), no Campus João Câmara, com quatro turmas do 10 ano do Ensino Médio Integrado (EMI), dos cursos técnicos de Informática, Eletrotécnica e Administração, no segundo semestre do ano letivo de 2015. O referido projeto foi motivado pela necessidade de fomentar reflexões, dinamizando o ensino da geografia e tinha como objetivo favorecer o processo de autogestão da aprendizagem por parte dos estudantes. Para tanto, fez- se uso da técnica de animação stop-motion como ferramenta pedagógica de autogestão da aprendizagem. A fim de alcançarmos o objetivo central, buscamos integrar nesse projeto atividades de ensino, pesquisa e extensão. $O$ trabalho resultou na produção de 22 animações. Ao final, percebemos que essa técnica de animação empregada no ensino de geografia como ferramenta pedagógica é capaz de suscitar a reflexão dos sujeitos sobre conteúdos explorados e estimular sua criatividade, pois requer estudo, planejamento e ação para que a animação seja construída.

PALAVRAS-CHAVE: Stop-motion, Prática pedagógica, Ensino de Geografia, Ensino Médio Integrado.

\section{THE USE OF STOP-MOTION AS A PEDAGOGICAL PRACTICE IN GEOGRAPHY EDUCATION IN THE CONTEXT OF IHC}

\begin{abstract}
This present work is an experience report of a teaching project developed in the discipline of Geography, at Federal Institute of Education, Science and Technology of Rio Grande do Norte (IFRN), in João Câmara's Campus, with four first year's classes of Integrated High School (IHC), in the technical courses of Informatics, Electrotechnical and Administration, On the second semester of the academic year of 2015. This project was motivated by the need to foster reflections, dynamising the teaching of geography and had as objective to help the process of self-management of learning by students.
\end{abstract}

Therefore, stop-motion animation technique was used as a pedagogical tool for self-management of learning. In order to reach the main objective, we seek up to integrate teaching, research and extension activities into this project. The work resulted in the production of 22 animations. In the end, we saw that this technique of animation used in geography teaching as a pedagogical tool was capable to evoke the reflection of the subjects on explored contents and stimulating their creativity, since it requires study, planning and action for the animation to be constructed.

KEYWORDS: Stop-motion, Pedagogical Practice, Geography Teaching, Integrated High School. 


\section{INTRODUÇÃO}

Em pleno século $\mathrm{XXI}$, vemos diante de nós inúmeros problemas possivelmente impensados séculos atrás, mas todos eles são consequências das ações humanas sobre o mundo em que vivemos, a partir de uma perspectiva desenvolvimentista embasada no sistema capitalista de produção. Por isso, esses problemas não se limitam ao século presente. Eles tiveram origem em concomitância com a evolução da espécie humana, agudizados pelo surgimento do capitalismo e sua reestruturação ao longo da história e se estendem junto com ele.

Os problemas aos quais nos referimos são de diversa ordem e natureza. Distorções que a sociedade na era do desenvolvimento técnico-científico-informacional ${ }^{1}$ ainda não conseguiu extinguir. Ao contrário, esse desenvolvimento acelerou e aprofundou alguns desses problemas, para não dizer que também criou outros, ou seja, a modernização produziu uma série de riscos que ameaçam a sobrevivência das variadas espécies existentes no planeta. Refletir a respeito, rever conceitos e atitudes emerge como uma necessidade do nosso presente.

A formação humana integral, omnilateral, também pressupõe reflexões dessa natureza, uma vez que elas permitem ao sujeito perceber-se inserido nas relações sócio-históricas que interferem sobre o meio ambiente. Reconhecimento necessário também à formação profissional, tendo em vista o caráter ético, responsável, consciente e cidadão de sua intervenção na sociedade. Ao voltamos nosso olhar para o Ensino Médio Integrado (EMI) dos Institutos Federais de Educação, Ciência e Tecnologia (IFs), a necessidade de reflexões sobre o meio ambiente se amplia.

Trabalhar, então, com animação, que é uma arte multimídia, se constitui em uma oportunidade de explorar os multiletramentos dos sujeitos em formação. Instigados pelo cenário ambiental do século XXI e motivados pela necessidade de fomentar reflexões, dinamizando o ensino da geografia, foi que nasceu a ideia de construirmos o projeto intitulado $O$ uso do stopmotion no processo de ensino-aprendizagem da Geografia.

O referido projeto foi desenvolvido com quatro turmas de alunos do 10 ano do EMI, no contexto do Instituto Federal de Educação, Ciência e Tecnologia do Rio Grande do Norte (IFRN), no Campus João Câmara. Esse projeto foi realizado com uma turma do curso de Eletrotécnica, duas de Informática e uma de Administração, nas quais a professora Joseara Lima de Paula ministrava a disciplina Geografia. Esse trabalho tinha como objetivo favorecer o processo de autogestão da aprendizagem por parte dos estudantes, favorecida pelo uso da técnica de animação stop-motion como ferramenta pedagógica.

A execução do projeto compreendeu o período de 15 de dezembro de 2015 a 04 de março de 2016, correspondente ao 3 o bimestre do ano letivo de $2015^{2}$, no Campus locus deste trabalho. Para tanto, buscamos no desenvolvimento desse projeto integrar atividades de ensino, pesquisa e extensão, envolvendo os estudantes ativamente nesse processo. Foi, então, a realização desse projeto que resultou no presente artigo, relato de experiência.

\footnotetext{
${ }^{1} \mathrm{O}$ termo "desenvolvimento técnico-científico-informacional" foi cunhado por Milton Santos e é discutido, dentre outras obras, no livro "O Brasil: território e sociedade no início do século XXI" (2011). Esse termo é usado pelo autor para caracterizar a união entre ciência e técnica que se deu a partir de 1970, desencadeando mudanças no território brasileiro, e que ganhou força com os recursos da informação em meio ao período de globalização.

2 Em virtude de greves anteriores, o Campus João Câmara iniciou suas atividades referentes ao ano letivo de 2015 em 19 de maio de 2015 e encerrou em 05 de abril de 2016.
} 


\section{A TÉCNICA STOP-MOTION COMO FERRAMENTA PEDAGÓGICA}

No cenário global, com a transformações no campo das tecnologias comunicacionais, mudanças significativas repercutiram, consequentemente, sobre os letramentos dos indivíduos na sociedade.

Para Rojo (2009), as duas primeiras mudanças, que se correlacionam, dizem respeito à rápida intensificação e à diversificação da circulação da informação, tanto nos meios de comunicação analógicos, quanto nos digitais. De acordo com Rojo (2009), essas vertiginosas mudanças trouxeram implicações sobre os modos de ler, de produzir e de circular os textos nas sociedades, alterando-os.

A terceira mudança refere-se à diminuição das distâncias espaciais em decorrência das mídias digitais e analógicas (ROJO, 2009). E a redução nas distâncias geográficas repercute, por sua vez, sobre os elementos culturais e informacionais, desconstruindo identidades populacionais.

Finalmente, a quarta mudança mencionada por Rojo (2009) refere-se à multissemiose, entendida como a pluralidade de modos de significar trazida para a leitura pelas possibilidades multimidiáticas e hipermidiáticas do texto eletrônico. A autora nos diz que diante das mudanças de produção e circulação de textos na sociedade, faz-se necessário relacionar a leitura do texto verbal escrito com um conjunto de signos de outras modalidades de linguagem que 0 impregnam, pois, os textos multissemióticos ultrapassam os limites dos ambientes digitais.

As mudanças apontadas por Rojo (2009) refletiram-se também na escola. Além disso, com a universalização do acesso à escola pública, os letramentos escolares sofreram impactos pela entrada no espaço escolar de letramentos locais antes desconhecidos e, portanto, desvalorizados pela escola. Assim, continuar com práticas de leitura e escrita de textos limitados a gêneros escolares seria, no mínimo, incoerente, dada sua insuficiência. Tornava-se necessário, então, ampliar e democratizar os eventos de letramento.

Para Antunes (2001), a escola muda e o professor educador assume um fundamental papel diante das mudanças, enquanto artesão de inteligências, condutor de desafios, capaz de despertar relações interpessoais, trabalhar valores e solidificar consciências. Em consonância com esse pensamento, Rojo (2009) nos explica que:

\footnotetext{
Neste sentido, o papel da escola contemporânea seria o de colocar em diálogo - não isento de conflitos, polifônico em termos bakhtinianos - os textos/enunciados/discursos das diversas culturas locais com as culturas valorizadas, cosmopolitas, patrimoniais, das quais é guardiã, não para servir à cultura global, mas para criar coligações contrahegemônicas, para translocalizar lutas locais. (ROJO, 2009, p. 115, grifos da autora).
}

A intenção é que a escola do presente século, que convive em meio a letramentos variados, estreite o contato dos alunos com os múltiplos letramentos. Isso para que se promova a participação dos sujeitos em variadas práticas sociais de utilização da leitura e da escrita e, nesse processo, forneça subsídios para que os alunos aprendam a fazer escolhas éticas e problematizem criticamente o discurso hegemônico. Assim, a escola formará cidadãos flexíveis, democráticos, protagonistas, multiculturais e poliglotas em sua língua (ROJO, 2009).

Mas, para que essa intenção seja materializada na prática, Rojo (2009) destaca que se deve trabalhar com diferentes formas de uso das linguagens (verbal, corporal, plástica, musical, gráfica etc.) e das línguas (falar em diversas variedades e línguas, ouvir, ler, escrever). Essa autora 
ressalta ainda que o trabalho precisa ser pautado em situações reais, a fim de desenvolver competências básicas necessárias à consciência cidadã. Desse modo, a capacidade de criação e de análise desafiam o aluno a pensar e repensar as práticas sociais. Subjacente a essa perspectiva encontra-se o conceito de multiletramentos.

O conceito de multiletramentos articula a multiplicidade cultural das populações (produções culturais letradas formadas por textos híbridos de diferentes letramentos e de diferentes campos) e a multiplicidade semiótica de constituição dos textos (textos compostos por variadas linguagens) por meio dos quais ela se informa e se comunica (ROJO, 2012). Essas características requerem novas capacidades e práticas de compreensão e produção, que, no passado, eram dispensáveis. As tecnologias digitais são um exemplo disso, como Lorenzi e Pádua (2012) pontuam.

[...] as tecnologias digitais estão introduzindo novos modos de comunicação, como a criação e o uso de imagens, de sons, de animação e a combinação dessas modalidades. Tais procedimentos passam a exigir o desenvolvimento de diferentes habilidades, de acordo com as várias modalidades utilizadas, criando uma nova área de estudos relacionada com os novos letramentos - digital (uso de tecnologias digitais), visual (uso das imagens), sonoro (uso de sons, de áudio), informacional (busca crítica de informação) - ou os múltiplos letramentos [...]. (LORENZI e PÁDUA, 2012, p.37).

Com os hipertextos e hipermídias, fazem-se necessárias novas ferramentas e novas práticas tanto de produção quanto de análise crítica do que foi produzido e circula na sociedade; que favoreçam a percepção acerca do cruzamento de interesses mercantis, estéticos e comunicacionais dos textos publicitários, por exemplo. Portanto, "São necessários novos e multiletramentos" (ROJO, 2012, p. 21).

A autora defende a necessidade de multiletramentos por reconhecer as características dos hipertextos e hipermídias: são interativos e colaborativos; transgridem as relações de poder e de propriedade estabelecidas; são híbridos, fronteiriços e mestiços.

Segundo Lorenzi e Pádua (2012), uma prática pedagógica alicerçada na alfabetização em multiletramentos deve fazer uso da tecnologia como objeto de ensino, considerando que suas possibilidades de intervenção são multiplicadas ao utilizar ferramentas digitais. De acordo com essas autoras, com a utilização das ferramentas digitais,

\footnotetext{
É possível formar redes descentralizadas para incentivar a interação; trabalhar com imagens (fator que modifica o conceito de comunicação); navegar por textos da web; utilizar animação para simplificar atividades complicadas e propiciar aos estudantes o sentido de serem autores dos seus trabalhos, uma vez que tudo pode ser publicado e exibido na internet. (LORENZI e PÁDUA, 2012, p. 40).
}

Desse modo, as possibilidades desencadeadas pelo uso das ferramentas digitais são capazes de colaborar com a formação humana por via dos multiletramentos.

Para Belloni (2005), um dos imensos desafios no campo da educação é a imprescindível reflexão para a construção de conhecimento apropriado à utilização crítica dos dispositivos técnicos das Tecnologias da Informação e da Comunicação (TIC). Ou seja, refletir sobre o potencial das TIC, buscando a integração dos seus recursos de modo crítico e criativo, aproveitando ao máximo suas potencialidades comunicacionais e pedagógicas é o desafio que adentra a escola marcando o presente.

Imbuídos por esse universo, entendemos que a escola é um espaço privilegiado de reflexão e vivência, sobretudo para a leitura crítica de mundo, independentemente do nível ou modalidade de ensino com a qual se trabalhe. Porém, defendemos que essa perspectiva ganha 
força ainda maior no cenário da Educação Profissional com vistas à formação para o mundo do trabalho, sobretudo no contexto do EMI, uma vez que pressupõe:

[...] uma formação completa para a leitura de mundo e para a atuação como cidadão pertencente a um país, integrado dignamente à sua sociedade política. Formação que, neste sentido, supõe a compreensão das relações sociais subjacentes a todos os fenômenos. (CIAVATTA, 2005, p.2-3).

Essa formação deve considerar, portanto, o ser humano inteiro, formando-o tanto para executar quanto para pensar, dirigir ou planejar em sua atuação profissional, conforme defende Ciavatta (2005).

Para tanto, pensamos em transformar a sala de aula da disciplina de Geografia em um tipo de "academia de ginástica", onde se exercita o cérebro a receber estímulos e desenvolver inteligência, recordando os ensinamentos de Antunes (2001). Por isso, os estudantes foram estimulados a pesquisar temas específicos, sorteados pela professora da disciplina, filtrar as informações essenciais e abordar o tema recebido a partir da animação com a técnica do stopmotion.

Compreendendo a importância de momentos vivenciais, o projeto reservou momentos para: orientação entre a docente da disciplina e os estudantes; minicurso sobre a técnica stopmotion; reunião em grupos e construção do material a ser apresentado; encontro para a socialização dos vídeos produzidos; e, publicização dos vídeos em canal no YouTube 3 para que outros indivíduos possam ter acesso e sejam instigados a refletir.

Escolhemos trabalhar com a técnica de animação conhecida como stop-motion por vislumbrarmos nela um elemento a ser explorado na perspectiva dos multiletramentos. Além de reconhecermos o stop-motion como um recurso midiático estratégico de comunicabilidade, sobretudo, para a educação ambiental de seus espectadores.

Para justificar essa escolha, recorremos a Barbosa Júnior (2011) quando nos diz que a animação é uma arte multimídia, pois combina diversas técnicas de produção. Segundo esse autor, o stop-motion é a mais antiga e, de fato, a verdadeira técnica de animação que ocorria pelo método de fotografar frame a frame.

Essa técnica surgiu na França, mais especificamente em Paris, no final do século XIX, por acidente, como falha técnica em uma das produções do mestre ilusionista George Méliès. Ao capturar algumas imagens na rua para produção de seus filmes, a câmera de Méliès parou por alguns segundos, congelando o movimento (PURVES, 2011). Esse acidente recriou um dos truques do ilusionista. Percebendo o feito, Méliès reconheceu a inovação e investiu em experiências cinemáticas variadas, criando novos mundos imaginários em torno da arte do movimento sintético, que seria conhecido posteriormente como stop-motion.

Conforme Purves (2011) resgata, a partir da destreza sobre a técnica, o mestre do ilusionismo não se limitava a criar filmes, mas recriava cenas documentais não capturadas por outras câmeras e também vendia produtos comerciais, fazendo uso da fantasia plena.

Nesse cenário, o stop-motion é definido como "a técnica de criar a ilusão de movimento ou desempenho por meio da gravação, quadro a quadro, da manipulação de um objeto sólido,

\footnotetext{
3 Esse canal pode ser acessado pelo endereço <https://www.youtube.com/channel/UCsw53uHuNDgJZ9KRaaDhZ5w>. Ele foi construído para compartilhar as animações utilizadas e também as construídas no contexto da pesquisa de mestrado intitulada "Educação Ambiental como elemento necessário à formação humana integral na Educação Profissional" e para além dela, como foi o caso das animações construídas a partir da realização do projeto $O$ uso do stop-motion no processo de ensinoaprendizagem da Geografia.
} 
boneco ou imagem de recorte em um cenário físico espacial" (PURVES, 2011, p.6). A ilusão do movimento se justifica pela leitura que o cérebro humano faz, pois "se duas imagens são suficientemente parecidas, o cérebro liga as duas, dando a impressão do movimento contínuo" (PURVES, 2011, p.7). Por isso, intenso trabalho é requerido de quem planeja e executa um projeto de filme a partir do stop-motion.

Purves (2011) e Barbosa Júnior (2011), em concordância, destacam que a atração de multidões de espectadores se dá nesse universo do movimento, em decorrência do fascínio que desperta a visão de um objeto inanimado que se move/ ganha vida. O "[...] movimento é a atração visual mais intensa da atenção [...]" (BARBOSA JÚNIOR, 2011, p.28). Nesse truque, como se fosse num passe de mágica, porém "[...] resultante de um longo processo evolutivo [...]", 0 filme ganha sua peculiaridade (BARBOSA JÚNIOR, 2011, p.28). E a relativa rusticidade sugere que uma mão humana esteve intimamente envolvida na sua construção.

Para aperfeiçoar suas produções, ao longo de sua experiência, Méliès agregou ao mundo dos brinquedos ópticos outras técnicas e materiais acompanhando o avanço tecnológico. De forma semelhante, fizeram alguns contemporâneos de Méliès, que marcaram a história da animação cinematográfica, no início século XX: Edwin Porter, Stuart Blackton, Émile Cohl, Ladislaw Starewicz, Willis O'Brien, entre outros.

Apesar dos inúmeros recursos e técnicas de animação ${ }^{4}$ que temos na atualidade para a construção de filmes, nesse trabalho, optamos pela adoção do stop-motion, pois ela demanda um trabalho artesanal rico em minúcias que pressupõem mais investimento de tempo e criatividade de seus mentores e executores do que com o uso de recursos tecnológicos de ponta. Além disso, com qualquer câmera fotográfica e um simples editor de vídeo no computador já se pode dar início à produção de uma animação. Tendo esses recursos em mãos, concebe-se a ideia, planeja-se o roteiro, selecionam-se os materiais necessários para construção das cenas a serem fotografadas, capturam-se as imagens, lançam-se as imagens no editor de vídeo, realizam-se os ajustes, incluem-se os efeitos (músicas, legendas, entre outros), define-se a velocidade de apresentação das imagens e a animação está feita.

Esse tipo simplificado de animação ainda hoje desperta a atenção e a curiosidade dos seus espectadores. Pela simplicidade em sua produção, pelo fato de exigir poucos recursos tecnológicos e pelo fato de ainda despertar a atenção do público, a selecionamos como técnica de produção de vídeos de curta duração, a qual os estudantes fizeram uso.

\section{STOP-MOTION NO ENSINO DE GEOGRAFIA}

O projeto foi desenvolvido pela professora Joseara, conforme informado anteriormente, em parceria com a pesquisadora Joaracy, mestranda no Programa de Pós-Graduação em Educação Profissional do IFRN, Campus Natal Central, que desenvolveu sua pesquisa utilizando, dentre outras ferramentas, a técnica stop-motion para a confecção de vídeos de cunho ambiental com graduandos em Tecnologia em Gestão Ambiental, sob a orientação da profa D.ra Ana Lúcia Sarmento Henrique.

Para tanto, a professora da disciplina selecionou alguns temas de caráter ambiental para explorar com os discentes do 10 ano, durante o 30 bimestre. Os temas foram: águas no Brasil (contraste entre a abundância e a escassez); degradação das águas oceânicas (sobretudo Mar Aral e Mar Morto); ilhas de calor e microclima urbano; aquecimento global; degradação dos grandes biomas (ação antrópica de desmatamento e poluição atmosférica).

\footnotetext{
${ }^{4} \mathrm{Na}$ atualidade, recursos como 2D, 3D e 4D têm dominado a arte da animação digital.
} 
Selecionados os temas e organizado o projeto, a professora de Geografia fez sua apresentação às turmas, explicando a metodologia de trabalho e a forma de avaliação a serem utilizadas. Feito isso, as turmas se organizaram em grupos e cada qual recebeu, após o sorteio, um tema a ser trabalhado e representado por meio da animação. A partir disso, foi dada continuidade ao projeto.

As atividades de ensino orientaram as atividades de pesquisa sobre o conteúdo a ser abordado nas animações, além de fornecerem os elementos básicos para o planejamento e construção dos vídeos com a técnica stop-motion. Essas atividades foram desenvolvidas tanto em meio às aulas da disciplina quanto a partir de minicurso, com duração de 4 horas, ofertado, em dezembro de 2015, sobre a técnica stop-motion e dicas de fotografia para as turmas envolvidas. Nesse minicurso, foram abordados os aspectos históricos de surgimento da técnica e suas características de execução. Após isso, foram apresentadas dicas básicas para fazer boas fotografias.

As atividades de pesquisa foram desenvolvidas, principalmente, pelos estudantes para apropriação do conhecimento já produzido em relação ao conteúdo do tema recebido a ser representado em uma animação por eles construída. Com base nos estudos realizados pelos estudantes, os grupos se reuniam, planejavam a construção do seu vídeo e apresentavam as ideias prévias à professora da disciplina, que lhes orientava como melhorar.
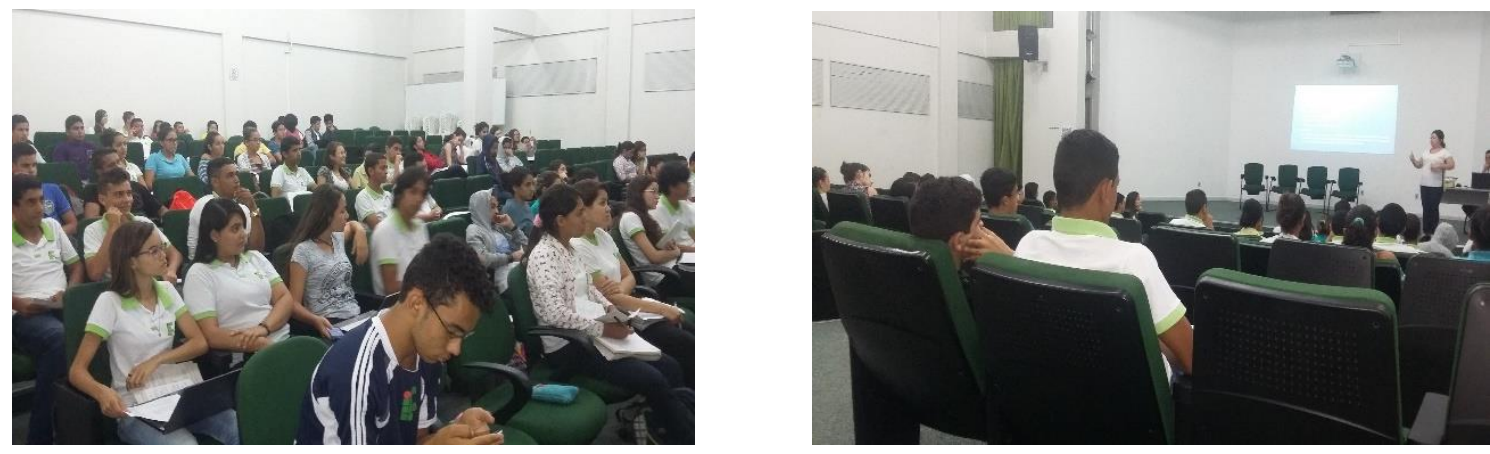

Figura 1: Minicurso sobre Stop-motion e Fotografia

Após a realização do minicurso, os discentes tiveram o período de 2 meses para construir suas animações. Encerrado esse período, uma banca de avaliação foi organizada para que os vídeos fossem apresentados, o que ocorreu em fevereiro de 2016.
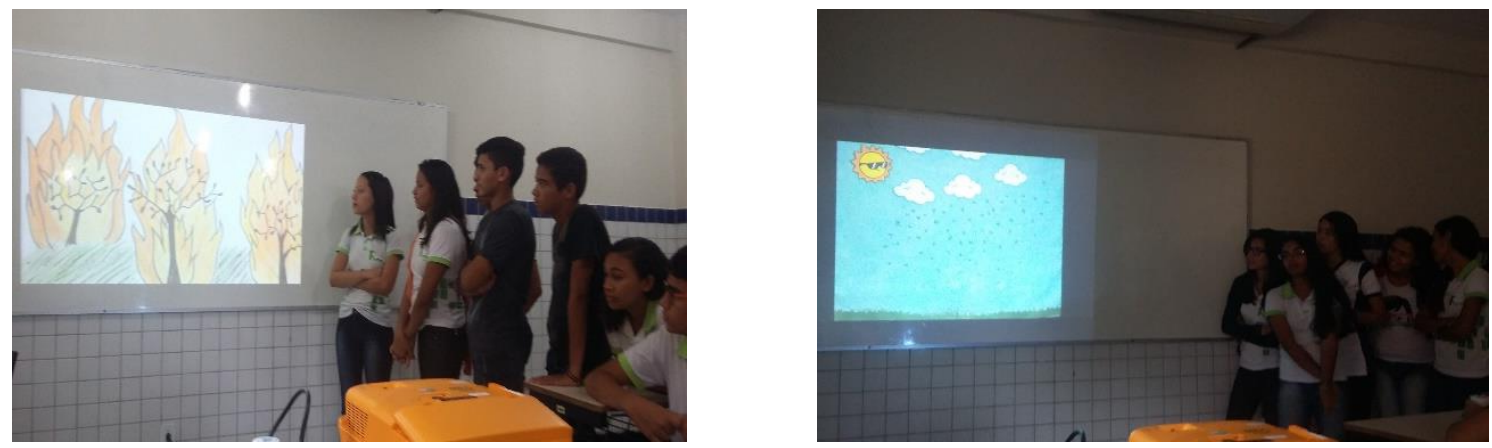

Figura 2 - Apresentação das animações construídas pelos estudantes 
A banca foi composta por três professores que avaliariam critérios distintos: conteúdo, aplicação da técnica de animação e qualidade das imagens usadas para compor o vídeo, conforme a Figura 3 expõe.

\begin{tabular}{|c|c|c|}
\hline $\begin{array}{c}\text { Professora responsável } \\
\text { pela disciplina de } \\
\text { Geografia }\end{array}$ & $\begin{array}{c}\text { Professora responsável } \\
\text { pela explicação sobre } \\
\text { Stop-motion }\end{array}$ & $\begin{array}{c}\text { Professor responsável } \\
\text { pelas dicas sobre } \\
\text { Fotografia }\end{array}$ \\
\hline $\begin{array}{c}\text { Organização, } \\
\text { planejamento } \\
\text { e execução } \\
\text { De 0 a 3 }\end{array}$ & $\begin{array}{c}\text { Animação } \\
\text { (aplicação da técnica) } \\
\text { De } 0 \text { a } 3\end{array}$ & $\begin{array}{c}\text { Fotografia } \\
\text { (qualidade das imagens) } \\
\text { De } 0 \text { a } 2\end{array}$ \\
\hline $\begin{array}{c}\text { Exploração do conteúdo } \\
\text { De } 0 \text { a } 7\end{array}$ & Abordagem do tema & Abordagem do tema \\
De 0 a 2 & a 3 \\
\hline
\end{tabular}

Figura 3 - Quadro de critérios utilizados para avaliação das animações

Em relação à apresentação dos vídeos pelos grupos, desde o minicurso, os estudantes foram orientados à relatarem para a banca como ocorreu o processo de planejamento e execução do vídeo, quais as dificuldades encontradas e qual a avaliação eles faziam de seu próprio trabalho.

Diferentemente dos demais avaliadores, membros da banca, a avaliação realizada pela professora da disciplina foi processual e final, pois ela acompanhou o desempenho e envolvimento dos estudantes ao longo de todas as etapas do projeto. Por isso, sua avaliação tinha um peso maior e somava até 10 pontos. A avaliação dos outros dois componentes da banca somava 5 pontos, cada. A média atribuída a cada grupo seria definida a partir da soma dessas 3 notas e sua divisão por 2 , resultando na nota do 3 o bimestre do grupo.

De acordo com as animações apresentadas pelos grupos, quando a banca solicitava e/ou orientava alguma mudança para a melhoria do vídeo, o grupo recebia o prazo de mais uma semana para devolver o vídeo após os ajustes e a sua média ser registrada.

Para a atividade de extensão, decidiu-se pelo compartilhamento das animações, produzidas pelos estudantes, em canal no YouTube específico construído para fomentar a reflexão de outros sujeitos a partir de animações de curta duração.

\section{CONSIDERAÇÕES FINAIS}

A escolha do stop-motion como ferramenta pedagógica se deu em virtude do caráter artesanal dessa técnica de animação, que requer planejamento e criatividade por parte de seus executores para atrair os expectadores. Além disso, é possível utilizar um software simples para se fazer a animação, como Windows Movie Maker, sem necessidade de gastos financeiros. Entendemos que empregado no ensino de Geografia, o trabalho com stop-motion é capaz de suscitar a reflexão dos sujeitos sobre conteúdos explorados, pois requer estudo da temática e planejamento para a construção do produto. Desse modo, fomenta a pesquisa, exercita o conhecimento e fortalece aprendizados.

Pelos relatos dos estudantes, no dia da apresentação, a maior dificuldade encontrada foi a reunião dos membros dos grupos para planejar e construir os vídeos. Em segundo lugar, em termos de dificuldade, estava o exercício criativo necessário para representar o tema sorteado 
por meio da animação, de forma clara e concisa, assegurando seus aspectos principais. O domínio da técnica para a execução do vídeo e sua edição, ficaram em terceiro e último lugar nas dificuldades mencionadas pelos discentes.

Em relação à avaliação que os estudantes fizeram do trabalho realizado por eles mesmos, alguns citaram que, quando começaram a confecção dos materiais para a animação, não se sentiam capazes de fazê-la e outros achavam que não conseguiriam, mas se surpreenderam ao ver o trabalho finalizado. Foi unânime o reconhecimento de que a construção da animação demanda envolvimento em um vasto trabalho artesanal e requer um sólido planejamento. Com isso, passaram a respeitar os trabalhos dos demais colegas, colocando-se no lugar deles para entender o grau de dificuldade vivenciado na construção do vídeo diante do seu resultado final.

$O$ trabalho resultou na produção de 22 animações, cuja duração média é de 1 minuto e 30 segundos, que abordaram os temas: contraste entre a abundância e a escassez de água no Brasil; degradação das águas oceânicas; ilhas de calor e microclima urbano; aquecimento global; e, degradação dos grandes biomas pela ação humana (desmatamento e poluição atmosférica). Isso demonstra que é possível trabalhar com essa técnica e que a mesma tem um rico potencial formativo.

Na dinâmica vivenciada percebemos que o trabalho mobilizou não apenas a criatividade e a capacidade intelectual dos sujeitos envolvidos, mas também aproximou os colegas de turma, pois pressupôs um trabalho em equipe. No processo de pesquisa e construção dos vídeos, grupos se reconfiguraram, alguns se uniram a outros e juntos somaram aprendizados. Assim, consideramos que aos estudantes foi dada a liberdade mediada de gerirem seu processo de ensino-aprendizagem.

\section{REFERÊNCIA}

Antunes, C. (2001). Como transformar informações em conhecimento (4. ed.). Petrópolis, RJ: Vozes, Fascículo 2.

Barbosa Júnior, A. L. (2011). A arte da animação: técnica e estética através da história (3. ed.). São Paulo: Senac São Paulo.

Belloni, M. L. (2005). O que é mídia-educação (2. ed.) Campinas, SP: Autores Associados. (Coleção polêmicas do nosso tempo; 78).

Ciavatta, M. (2005). A formação integrada: a escola e o trabalho como lugares de memória e de identidade. Revista Trabalho Necessário. Rio de Janeiro, ano 3 (no 3), pp.1-20. Recuperado em 20 janeiro, 2016, de http://www.uff.br/trabalhonecessario/images/TN_03/TN3_CIAVATTA.pdf

Lorenzi, G. C. C. \& Pádua, T. R. W. (2012). Blog nos anos iniciais do fundamental I. In R. Rojo \& E. Moura. (Org.) Multiletramentos na escola. São Paulo: Parábola Editorial.

Purves, B. (2011). Stop-motion. Porto Alegre: Bookman. (Animação Básica 2).

ROJO, R. (2009). Letramentos múltiplos, escola e inclusão social. São Paulo: Parábola Editorial.

Rojo, R. \& Moura, E. (2012). Multiletramentos na escola. São Paulo: Parábola Editorial.

Santos, M. \& Silveira, M. L. O Brasil: território e sociedade no início do século XXI. Rio de Janeiro: BestBolso. 